\title{
Special Educational Needs: A New Way of Educating
}

\section{Jose Manuel Salum Tome}

Department of Education, Faculty of Education, Universidad Católica de Temuco / Instituto CFT Teodoro Wickel, Temuco, Chile

\section{Email address:}

josesalum $@$ gmail.com

\section{To cite this article:}

Jose Manuel Salum Tome. Special Educational Needs: A New Way of Educating. International Journal of Education, Culture and Society. Vol. 6, No. 1, 2021, pp. 1-8. doi: 10.11648/j.ijecs.20210601.11

Received: December 17, 2020; Accepted: January 13, 2021; Published: February 2, 2021

\begin{abstract}
In the context of Professional Technical Education, Dual Modality has been a commitment of the Chilean Ministry of Education to improve Professional Technical training in High School. The change has involved a curricular innovation around the development of basic competences where, in addition to the teacher and the traditional classroom, other agents and other scenarios that share the work of teaching concur. In this context, the research consigned, according to its objectives and methodological formulation, describes the characteristics of the Dual Professional Technical training of the Administration specialty of the Monseñor Guillermo Carlos Hartl Educational Complex of the Pitrufquén commune, in Chile. It is intended to investigate the effectiveness of the integrated curriculum through the assessment of achievement of the basic competencies of students who are in the 4th Middle Year of said specialty (with Dual mode), in direct relation to the required graduate and professional profile and in contrast, with that of students of the specialty of "Electricity", without the Dual Modality. What is demonstrated by this research is that students achieve comprehensive development with the development of social, generic and technical skills, which will allow each one to face the world of work as a competent and comprehensive person.
\end{abstract}

Keywords: Special Educational Needs, Integration, Inclusion, Public Policies

\section{Introduction}

The recognition of the value of the diversity of the people that make up our society grows more and more, however, much remains to be done in relation to how to attend to this diversity. Equalizing opportunities, addressing the problems that hinder learning, and managing to address the needs of all students are difficult challenges to meet, especially when it is common and accepted practice to label, separate, distinguish, or discriminate, therefore, to achieve a school. inclusive is essential to build an inclusive society, that is, a truly democratic and equitable society [9]. This article reports the results of a study that aimed to analyze the evolution of the public policy discourse on Special Educational Needs in Chile from the year 2000 onwards, identifying the main concepts, emphasis and evolution of the political debate. Also, he analyzed the correspondence between political discourse, action and public investment from the point of view of their distinctions and orientations. This analysis allowed us to appreciate how some of the most important policy instruments of the administrations have been implemented in the field of education, effectively taking charge of the integration and inclusion of students with special educational needs.

A review was made of different sources referring to government policies that have focused their attention on Special Educational Needs in Chile, hereinafter SEN, and then made a comparison with the main orientations of international discourse and debate on the subject through a hermeneusis of information reviewed and systematizing of public policies in the field of NEE in Chile. However, the importance that the topic of inclusion has acquired in the educational and social sphere has been key in politics in recent decades.

This study set out to evaluate the importance and emphasis given by the political authorities of the last administrations to grant opportunities to all citizens without distinction. It is an issue that has been gaining ground in the context of new demands for equality and the recognition of historically marginalized social groups. In consequence, this work contributes a subject little discussed in the literature and provides an overview of what is done and said in Chile in relation to the SDN. This in order to position a topic of 
increasing interest and relevance in the country.

In addition, the level of correspondence of politics in Chile with the international discourse on the subject is addressed, thus helping to examine possible differences and enrich the current national approach to take on the challenges and contribute to the discussion on regulations, behaviors or practices that they promote inclusion, participation and learning without discrimination.

Therefore, Inclusive Education at its origins and for a long time, maintained an elitist character, based on the exclusion of that population that did not meet the requirements for education. When the systems began to incorporate previously excluded groups of the population, they were generally structured in dual systems, which, recognizing the right of all people to education, established different policies for groups in situations of inequality. In this stage of development, based on segregation, special schools emerged, establishments that catered only to students with certain SEN, maintaining the distinctions. Then, some measures aimed at school integration were developed, based on a spatial and physical integration of the students, but not substantive. Thus, little by little, the approaches and orientations towards inclusion in school began to transform, increasingly incorporating the participation of people, regardless of their characteristics [5].

\section{Special Educational Needs}

Contemporary democratic societies are characterized by their increasing levels of openness to diversity, which constitutes an enormous wealth to face social complexity. The educational policies of recent years in Chile, have incorporated issues related to integration and diversity, the concepts that inspire these policies are associated with equity, social justice and democracy, social demands that require education to take charge. In this way, problems such as exclusion have been incorporated into policies that attempt to correct discrimination problems [7].

This study collaborates in this direction, because it allows evaluating and evaluating, through documentation and empirical evidence, the discourse of the last Chilean governments in the field of education for all, contrasting their orientation with the international debate and identifying some gaps and deficits that constitute challenges in this matter.

We understand by Special Educational Needs (SEN), the set of pedagogical measures that are put in place to compensate for the difficulties that a student presents when accessing the curriculum that corresponds to him by age. These difficulties are superior to the rest of the students, for various reasons: disabilities, serious conduct disorders, high intellectual abilities or due to late integration into the educational system.

Measures can be permanent or temporary, access adaptations to the curriculum, or significant curricular adaptations in various areas of the curriculum. According to the current law on educational matters, at present, we speak of students with Specific Needs for Educational Support when we refer to all the previous casuistry and differentiating with the term NEE only those students with disabilities or conduct disorders.

We all have educational needs, but some students or people have special educational needs. These have a dynamic character, since they appear between the characteristics of the subject and what the study system or program provides. The SEN are not always related to a learning difficulty, they can also occur because the student grasps and learns too quickly, so he needs to be advancing and learning more things than others. In both cases, curricular adaptations must be made and the appropriate work methodology or strategy must be sought to satisfy those special educational needs.

Students with special educational needs are those who require, for a period of their schooling or throughout it, certain specific educational supports and care derived from disability or serious conduct disorders. This definition is updated with the new Instructions of March 8, 2017, in which this is referred to as: one that requires, for a period of his or her schooling, specific attention, derived from different grades and types of personal capacities of a physical, mental, cognitive or sensory nature.

The intellectual disabilities involves a number of limitations on the skills that the person learns to function in your daily life and allow you to respond to different situations and places. People with intellectual disabilities have a harder time learning, understanding and communicating than others. Intellectual disability is not always permanent, that is, nor for life, with therapeutic work and appropriate care from the appropriate specialists, great progress can be made and has an important impact on the life of the person and her family.

The intellectual giftedness is defined by Joseph Renzulli (1994) and for possession of three basic sets of characteristics closely related and with an equal emphasis on each of them:

1. A higher than average intellectual capacity, in relation to both general and specific skills.

2. A high degree of dedication to tasks referring to perseverance, resistance, knowledge, show more effectiveness in the use of metacognitive processes.

3. They have a superior ability to solve highly complex problems, applying the knowledge they already possess and their own reasoning skills.

4. They have a great ability to abstract, conceptualize, synthesize, as well as to reason, argue and ask.

5. Present great curiosity and a constant desire for the why of things, as well as a wide variety of interests.

6 . They have a high memory.

7. They present an early maturational development and high in perceptual-motor, attention, communication and language skills.

The cases of "high intellectual abilities" (gifted) are also considered as people with specific needs for educational support, since in this case, the curricular contents tend to be easy or even boring for these students, who have greater capacity. 
Therefore, the following are proposed as solutions:

1. Acceleration: The student is advanced a course, to compensate his greater capacity. Sometimes more than one acceleration is necessary.

2. Curricular adaptation: The student works in programs to complement their normal studies. Likewise, they are considered as the modifications that are made on the ordinary curriculum, necessary to respond to the learning need of each student.

Just as there is a special educational need (SEN) associated with intellectual disabilities, there are more examples:

1. SEN associated with physical disability

2. SEN associated with hearing impairment

3. SEN associated with visual impairment

4. SEN associated with autism spectrum disorders

5. SEN associated with serious conduct disorders

6. SEN associated with serious developmental disorders

7. SEN associated with communication disorders

8. SEN associated with attention deficit disorders with or without hyperactivity

9. SEN associated with other mental disorders.

Integration is a right, not a privilege, Declaration on World Disability Day, (1997). Special Educational Needs are related to the special aids and resources that must be provided to certain students who, for different reasons, face barriers to their learning and participation process. These students can be street children, working children, with some type of disability, from indigenous populations.

It is essential to understand the concept of Special Educational Needs (SEN) and identify the value that it has acquired over time. Although it has a long history, it is only recently that it appears as a matter of formal state concern, coming to occupy an important place in political discourse and in the design of emerging intersectoral programs.

The notion of "Special Educational Needs" appears developed in the field of education for the first time in 1978, in the Warnock Report (1978). This report comes after a research committee chaired by Mary Warnock was asked to “... analyze educational benefits for children and young people with disabilities in England, Scotland and Wales, considering the medical aspects of their needs and the appropriate means to their preparation to enter the world of work; estimate the most effective use of resources for such purposes and make recommendations" [8].

This report is considered one of the most important milestones in the change to a contemporary notion of special education, broadening its focus, it not only considers the students who present learning difficulties with a personal disability, but also a significant number of students that require special attention due to a multiplicity of circumstances. Thus, a new conception of SEN arises, which Warnock defines as follows: a "student with special educational needs refers to those students who present any degree and type of learning difficulty, in a continuum that goes from the mildest and transitory to the most serious and permanent".

The concept of SEN appears first in countries with a high level of development, and then expands to the rest of the world. In this sense, the incorporation of a new conceptualization and consequently the influence of the international debate has been important for the rest of the world, marking certain emphases and transformations that are relevant to the understanding of SEN.

This new approach impacts Chilean education, albeit with a significant time lag. The National Special Education Policy document [13] mentions a new idea of special education, leaving behind the visions that consider special education and general education as separate realities, as well as the implications of the Warnock report on our educational system.

Special Education is understood in a new way as a result of the Warnock report of 1978, since it affirms that the aims of education are the same for all boys and girls, regardless of the problems that are in their development process. Therefore, education must respond to the diverse educational needs of students to achieve its purpose [12]. In accordance with the above, concepts such as disability and SEN have been redefined and developed under different models over time.

The concept of disability is relative and varies according to the historical and social context, however, it is possible to distinguish at least three treatment models. A first model is the so-called 'of the absence', which considers that the life of a person with a disability does not deserve to be lived, therefore, society can do without them. A second model is that of the 'rehabilitator', who considers that the cause of a disability is scientific and although it aspires to the integration of a person with a disability, this objective is achieved to the extent that people manage to eliminate or hide their difference. Finally, the 'social model' is mentioned, which considers that the causes of disability are predominantly social. Under this model, boys and girls with disabilities should have the same opportunities for development as children without disabilities, therefore, the Education must tend to be inclusive, that is, adapted to the needs of all [15]. So we can affirm that the move from exclusion to the inclusion of people with disabilities has not been an easy process, its evolution has required a long period of time that is still under development.

It is important to note that recently the use of the concept of barriers to learning and participation has been privileged, instead of SEN, traditionally linked to disability. This new concept alludes to the factors and obstacles of the context and the educational response that hinder or limit full access to education and learning opportunities for a large number of students $[10,11]$. For example, authors such as Booth and Ainscow [3] do not share the use of the SEN concept since they consider that it is to give a label to a student thus generating low expectations, therefore, if educational difficulties are attributed to student deficits the barriers to learning and participation that are present at all levels of the educational system are no longer considered.

School integration, despite its limitations, has configured a previous stage of development that later gave way to greater inclusion; However, both concepts have been used interchangeably in the literature associated with students 
presenting SEN. Currently a clear conceptual difference has been raised that is important to know and identify.

In the educational field, the step from the notion of integration to that of inclusion is essential. Usually, the use of the concept of integration refers to the search for the student's adaptation to a school situation, that is, the establishment provides support through a set of appropriate and necessary means so that it can develop its capabilities in the best possible way. Therefore, it is considered that in the notion of integration, the emphasis is on the student. The use of the concept of inclusion, on the other hand, supposes a greater context that implies the adaptation of the educational area, that is, adapting all the necessary elements so that that institution has the capacity to educate the population as a whole, whatever its characteristics. personal. The notion of inclusion, therefore, places its emphasis on the institution and how it is capable of attending to the diversity of students, whether they have SEN or not [4].

In our country, the first steps in addressing SEN were taken during the eighties, when the first students with sensory disabilities were incorporated into regular education. However, this progress was not without problems, among them, the lack of material resources and insufficient teacher training. In this sense, although policy initiatives promoted integration, true inclusion was not achieved. That is, although the excluded were incorporated into the educational system, they did not develop the 8 necessary adaptations, distancing themselves from an educational inclusion approach that is based on the adaptation of teaching systems to respond to the diversity of needs of individuals. [1]

Starting in the 1990s, the process of Educational Reform began in Chile. Its purpose was to achieve greater equity and quality in education, for which it committed to carrying out actions that favored social integration [12]. During that same decade, world organizations such as the United Nations, UNICEF, UNESCO, and OREALC-UNESCO promoted declarations, proposals, and reports that aimed to advance towards more inclusive and inclusive educational systems, which have served as a basis and orientation for the implementation of national plans.. The Curricular Reform of our country, started in 1996, addressed the curricular frameworks of education at its different levels, including basic, middle and finally kindergarten education. However, special education was not included in this reform [6].

\section{Scope of Special Education in Chile}

Special Education in Chile has presented a series of progress, but also imbalances and limitations in its implementation and definition in the different legal frameworks. For example, the Organic Constitutional Teaching Law LOCE, of 1990, does not rule on the role that Special Education should play in the framework of the country's educational system.

Law 19,284 of 1994, on the Social Integration of People with Disabilities, encourages the incorporation of students with disabilities in basic schools and high schools through
Project strategies, defining special education as a "differentiated modality of general education, characterized for constituting a flexible and dynamic system that develops its action preferably in the regular education system... "(art. 26), contradicting what is established in the Subsidies Law issued a few years later, in 1998, in which the Special Education is narrowly conceptualized as a differentiated modality of basic education [13].

Despite their imbalances and contradictions, these regulations mark the beginning of the incorporation of students with disabilities into regular schools that present an Educational Integration Project, that is, they enable access to regular education by granting additional special supports necessary for them to progress in the common study plan [6].

Our country has experienced a series of changes in relation to Special Education, among which are: a significant increase in the subsidy for students, increase in the coverage of integration of students with Special Educational Needs to the regular system, training programs to teachers and the elaboration of specific regulations that favor educational integration [12].

During the last decades, not only in Chile but also throughout Latin America, transformations have been introduced in the educational field, generally, giving special emphasis to the objectives of quality, equity and access to diversity in education [16]. To progress towards these objectives, the school "has to achieve the difficult balance of offering an educational response that provides a common culture for all students, but at the same time comprehensive and diversified; to avoid discrimination and inequality of opportunities while respecting their individual characteristics and needs" [1].

The inclusive approach is based on the valuation of diversity, which recognizes all human beings as different, and that such differences are not exceptions. The school, therefore, must develop teaching strategies in order to address all this diversity of characteristics and needs present in the students (Duk, 2000). For its part, this concept of diversity suggests that all students show educational needs of some kind; some habitual and identical for the majority, and others own and individual, that could be special.

Consequently, inclusion is what allows identifying and minimizing barriers to learning and participation, maximizing resources to help in both processes. Barriers, as well as resources to decrease it, can be found in all elements and structures of the system: within schools, in the community, and in local and national policies [3].

\section{Public Policy Inclusion: Gaps and Mismatches}

In Chile, the topic of SENs has been progressively incorporated and deepened in the public policy agenda in recent decades, as evidenced by new regulations and laws related to the subject. It is, therefore, a matter of significant importance, which has been attracting the attention of 
authorities. The way in which the issue of SEN is conceptualized from the political authority is key. There is no neutrality in the use of concepts, since the definitions and assumptions imply decisions about how the topic is approached. Hence the importance of analyzing political discourse and how it is later expressed in public policy initiatives.

Undoubtedly, inclusion presents a great challenge not only in the educational field, but as a society that respects human rights, today it is not enough to integrate, it must be included, for this reason the importance of making a clear distinction between both concepts.

\section{Education and Inclusion in Chile}

Now, the Chilean educational system is incredibly diverse. For a few years, efforts have been made to generate an education that is friendly to the different realities of the students and that understands the multiplicity that occurs in the classroom. But the term "inclusion" has been gradually expanded, making it difficult to plan teaching for diversity, and at times, leaving in the dark certain groups that should be a priority in advancing national education.

That is the case of students with special educational needs or SEN, a group of boys and girls in our country who require a little more from society. According to the School Integration Program (PIE) of the Ministry of Education, a student who presents SEN is one who needs additional help and resources, whether human, material or pedagogical, to conduct their learning process and contribute to the achievement of the goals. of Education (Decree No. 170/09 MINEDUC).

Along with the development of definitions and specifications of these needs, the number of children requiring special education has grown exponentially. An indicator of this increase has been the number of students with these requirements that are covered by regular education: in 1997, 3,365 students joined the system, while in 2005 , this figure amounted to 29,473 children.

According to the academic of the Differential Education Degree, Iván Cifuentes (2020), this increase is explained in part by the refinement of the diagnosis of SEN, ensuring that "it is very likely that children who previously had no diagnosis and studied in ordinary schools, now they have it, giving us the possibility to satisfy their needs and improve their learning".

Considering this context, important questions arise on the horizon: Does the Chilean educational system take charge of the education of these children? Are we doing enough to ensure your learning?

\section{School Admission in Chile}

The process of admission to schools was a really horrible, traumatic experience, because we had come from London with an unregulated Cleme, learning about this diagnosis of autistic disorder, without knowing anything about it. Also facing what this means economically: paying for therapies, remedies and neurologists, and also facing how difficult it is to have a child like that, who has many difficulties on a daily basis. Finding a garden was a challenge, and when we found the garden, two months later they tell us that by age it is up to them to apply to a school, and we were hopefully getting her to go to the garden accompanied, how could we

"The better a school integration program is, the more clarity they will have on how to approach inclusion, how it is carried out, what the rules are."

However, due to age, he actually had to apply so as not to be left out. "I did not know what integration was at that moment, I did not know anything, someone started talking to us about schools with integration. They said it was a thing of obligation by law to be welcomed. It was like hitting blinds. We started looking for schools like crazy. We applied for Cleme in schools that we now know was a mistake. And some very little transparent schools, I asked if they had integration and they said yes, and there I paid for the process and did everything and then they told me "how do you bring this child". We live bad experiences and in some schools mistreat", remembers Clemente's mother.

And so they applied to many schools, in different parts of Santiago: "We knocked on many doors, a super thankless and super difficult experience, where parents also do not know what to do or how to seek help. My husband wrote a letter of relief and shared it on Facebook, and there many people recommended schools to us", among them, the school where Clemente is currently located, the Padre Hurtado School.

In this school, the admission process was different: "We had interviews with the head of the school's integration department, who is a differential educator and who carries out the program and knows the subject. Then, the rector of the school interviewed us. And she went twice, with a psycho-pedagogue, to see Clemente in the garden room, because she understands that, if for a neurotypical child it is already difficult to expose himself to all that stress of applying to school, for a child with special needs it is even more so; So, they will see him in the garden where he was used to being every day. And they go like this, half infiltrated, to look at him. That is very good because that way he did not feel exposed, "says Daniela.

"Having a child with special needs is a very challenging day-to-day job, both for schools and for us parents, where we all have to be involved, the truth is that the school has very good will, but there are things that they're still in diapers. "

After that process, Daniela tells that she had many bad experiences, but also establishments with good intention and welcome. She concludes: "The better a school integration program is, the more clarity they will have about how they approach inclusion, how it is carried out, what the rules are. The more experience an integration school has, the less fear they have for the students who apply, and the more clearly they can explain to the parents from the child's entrance, to how their school development will be, how the demands will be of the child, what are the days, and everything else".

The day to day at school according to Daniela Maino (2020).

"They told us that we had stayed and so, without any 
special requirement. In March he would enter like any other child, subject to evaluation, and on the way he would see if he would need a tutor, as happens in some cases, recalls Daniela, adding" It was really the maximum happiness because when a school accepts you, you feel that you earned the Kino, the Lotus, all together because, after so many doors are closed in your face, the truth is that it is incredible".

Clemente is nine years old and is in second grade: "From the end of pre-kindergarten, he started going to school with a tutor. Our school increasingly requires children with special needs to be accompanied by a tutor because they have realized that with a mediator and everything, sometimes they cannot cope, it has been a good solution for working in the classroom," says Daniela. However, "this is very expensive, it is the same as paying for another school", and points out that it also has a special day, from 8 to 14 hours. "In inclusive schools, the child with special needs is one more, and is treated as such, and has the same day, the teacher is prepared and everything has to work as a clock, here we are in diapers at that. One here meets schools with good will that have spent many years working with children with special needs and who are already managing themselves a little better, "says Daniela.

Where are we and where are we going?

Since the first decade of the century, the Chilean government has made evident efforts to improve diversity in the educational system. Specifically with the PIE, which lays the foundation for what is known as Special Education. Likewise, the enactment of Decree 83 is highlighted, which broadens the concept of diversity in the classroom.

For Professor Cifuentes (2020), one way of measuring the real impact of these policies is through four key moments in the development of a student with Special Needs: entering the system, remaining in it, progress in learning and the exit or exit of the system. In this sense, he points out that " in Chile we have ensured that children with SEN enter and remain in our educational system. The challenge that follows is to achieve that the students progress in their learning and that they can leave the system".

But how do we make that student progress? According to the academic, the answer is found in the training of new educators and in curricular diversification,

... debe be a profound transformation of the educational activity through flexibility and diversification of the curriculum. The emphasis then falls on the training of educators, creating autonomous, flexible professionals who work collaboratively".

Cifuentes (2019), goes one step further, ensuring that a fundamental axis in the future of Special Education is research and that, without it, the system will not advance.

... We must generate research on the subject, where we can demonstrate that inclusive education really works and represents a change for children with special needs. Because it is a relatively nascent topic and is constantly advancing, there is no research, and that is what should be done to improve the system.

The approaches to educational reform have been uneven when putting educational inclusion into practice, [5] attribute it to the different phases that inclusion includes, for this they quote Fernández (1998) who points out four phases of educational responses towards inclusion. The first phase called exclusion, a second phase of segregation, after integration and finally the fourth phase of restructuring, where inclusive education is found.

It is necessary for the current school system to continue working towards inclusion, ensuring that it is effectively incorporated at all levels, modalities of the Chilean school system and transversally in educational policies, since it is the only one capable of restructuring not only the infrastructure of the environment, but to modify a society that still segregates towards a truly democratic one.

\section{Recommendations for Teachers}

It is known that it is not an easy challenge for teachers, since they also have many children in their room, who are restless and sometimes difficult. What I would ask them to do is be empathetic with the families, be open to listening to all kinds of advice on how to get that child off the ground, hopefully they will meet with the family and with the specialists who see the child. Never believe that a child with a type of disability cannot learn or that it is a lost case. That deep down they never lose hope that they can transmit things to their children, if they believe that all children can learn, and they trust that, it is key, because if they believe in that, they will do their best to children learn".

In summary, a teacher who has a child with special educational needs in his / her classroom should: "Train, get to know the child in front of you, try to understand him, for that reason, rely on specialists and always, always, be aware that this child can learn".

Having a child with special needs is a very challenging day-to-day job, both for schools and for us parents, where we all have to be involved, the truth is that the school has very good will, but there are things that they are still very nascent. With my husband we have tried to get very involved in the school, today we are integration delegates, we work with the school to see how we can improve all the systems. We also work with integration families, in gathering information, we have prepared many documents, several questionnaires to obtain information and work based on it. It is a constant challenge, we read about it, I now live well day by day, I get the most out of current moments.

\section{Conclusions}

In relation to the main findings, it was possible to build an educational care model not only for the students who present SEN, but which responds to the entire population of students in the establishment, based on a new way of welcoming students with a glance fairer and more egalitarian, which allows us to reflect that in order to achieve an inclusive culture, it is necessary to change the thinking of professionals, from a model that works for the majority of 
students, providing something additional for those presenting SEN, for an approach that provide efficient and accessible learning opportunities for all, so that any student can participate in life in the classroom.

On the other hand, as a general reflection raised by this article in relation to processes of construction and situated cognitive configuration, it can be established that through the experiences of the possibilities of changes and transformation towards practices and an inclusive culture of the participants, they focus on personal efforts rather than in a general teaching context. Each subject as part of the educational community acts from fragmentation and incidental connection, there being an individualism to solve and solve school situations that arise in daily life. In the case of the students, these are passive agents in the teaching processes, who expect from the teachers the indications of what, when and how to do a certain activity, which hinders the development of their autonomy and freedom of learning, as well as decision-making and informed opinions. On the contrary, when the students have been granted some degree of freedom and participation in school activities, they are not able to face the possibility of autonomy, waiting for the solutions and expected results from teachers for a given situation.

In the case of parents and guardians, they are not directly involved in the education of their daughters and delegate all the commitment to the school, taking into account that the family should be the main responsible for the transmission of principles, values and knowledge..

Another relevant element is the homogenization as relational dynamics, this from the implementation of educational practices designed for the course group as a whole, with similar and undifferentiated cognitive processes, which tends to be the main reference and model in the subjects of the educational community, following a common and repetitive logic, where the roles, duties and responsibilities of the students and teachers are preestablished.

Furthermore, according to the dimensions of the research, the main actions that facilitated educational inclusion in the establishment were mainly a change of focus by teachers, by incorporating playful and concrete activities into their methodological practices, based on the suggestions issued by the students, parents, specialists and the teachers themselves.

Furthermore, it is important to consider other topics that are worth mentioning and are related to the educational system. The teachers stated that it is the system itself that does not allow inclusive practices, due to the series of requirements that exist such as the SIMCE, the number of students per room and the large workload that makes it difficult to prepare materials and activities for lessons. At the same time, faults can be determined in the teaching competencies when accepting the SEN, showing a lack of knowledge about the subject; as well as the low diffusion of an inclusive culture in the MINEDUC program plans is decisive, and the establishments must take advantage of programs according to their own educational projects. This reality disorients schools that do not make differences in their classrooms and that are not governed by Decree 170 (Regulation derived from Law 20.201).

On the other hand, by listening to the proposals and perceptions of the students at the beginning of the research, it was possible to establish that the girls often feel misunderstood in their homes and at school, which damages learning and the construction of their own knowledge and ideas. This fact is also related to what parents and guardians have stated, establishing a strong critical knot in relation to communication within families, generating misunderstanding and disagreements between the students and the home.

In relation to the above, to address this reality in an inclusive way, it is important to generate instances of feedback where students are listened to, in this way, develop a more democratic and participatory education, especially of the main actors: male and female students. In agreement, the fact of promoting an inclusive culture allows greater participation of students and, therefore, they can make their opinions, feelings and concerns known, generating learning that is closer and more humane, according to both emotional and educational needs. of boys and girls. So we can conclude that inclusive culture fosters a fairer, more equitable and equal education in educational communities. This contradicts the reality that currently exists regarding inclusion, where different authors agree that there is a stagnation on the subject (Revista Latinoamericana de Educación Inclusiva, 2014).

Therefore, it is necessary to promote investigative instances in relation to inclusion, that are born from the school realities themselves and that account for the perceptions and experiences of those directly involved. It is necessary to generate a reflection in everyday life about the educational culture, its organizational models and, in the same way, look at the educational practice in order to examine the qualities and expectations that teachers and specialists have about students with SEN. Processes that also suppose a profound change in the conceptions, precisely of the professionals.

In short, it was possible to build an inclusive educational care model that is supported by the construction of different stages and their subsequent analysis. It can be used as a guide for other initiatives on the attention of SEN, based on this educational exploration, promoting new research perspectives related to inclusion, as well as the methodology used, so relevant to transform educational realities, starting from of the participatory research of the communities.

\section{References}

[1] Blanco G., Rosa La Equidad y la Inclusión Social: Uno de los Desafíos de la Educación y la Escuela Hoy REICE. Revista Iberoamericana sobre Calidad, Eficacia y Cambio en Educación, vol. 4, núm. 3, 2006, pp. 1-15 Red Iberoamericana de Investigación Sobre Cambio y Eficacia Escolar Madrid, España. 
[2] Blanco, R. (1999). Hacia una escuela para todos y con todos. Boletín del proyecto principal de educación para América Latina y el Caribe, 48 (1), 55-72.

[3] Booth, T. and Ainscow, M (2002) Index for INCLUSION: Developing Learning and Participation in Schools. Centre for Studies on Inclusive Education, United Kingdom.

[4] Casanova, M ${ }^{a}$ A (2011). Educación inclusiva: un modelo de futuro. Madrid: Wolters Kluwer. 291 págs.

[5] Escribano, A. y Martínez, A. (2013). Inclusión educativa y profesorado inclusivo. Aprender juntos para aprender a vivir juntos. Madrid Narcea, $152 \mathrm{pp}$.

[6] Godoy, M., Meza, M. y Salazar, A. (2004), Antecedentes históricos presente y futuro de la Educación Especial en Chile, MINEDUC: Santiago.

[7] Infante, M., Matus, C., \& Vizcarra, R. (2011). Reasoning about the idea of difference in Chilean educational policies. Universum, 26 (2), 143-163.

[8] Informe Warnock (1978) sobre educación especial: Special Educational Needs. London: HMSO (informe del Comité de Investigación sobre la Educación de Niños y Jóvenes Discapacitados).

[9] Juárez Núñez, José Manuel and Comboni Salinas, Sonia La influencia de la Organización para la Cooperación y el Desarrollo Económicos en la Reforma Educativa. Argumentos (Méx.), Abr 2014, vol. 27, no. 74, p. 153-189. ISSN 01875795.
[10] Mineduc (2004). Sample-level study on the quality of the Educational Integration Process. Santiago de Chile: Author.

[11] Mineduc (2004). Commission of Experts on Special Education: New Perspective and Vision of Special Education. Santiago de Chile: Author.

[12] Mineduc (2005): National Policy of Special Education. Our commitment to Diversity. Santiago de Chile: Author.

[13] Mineduc (2004). New Perspective and Vision of Special Education. Report of the Committee of Experts on Special Education. Ministry of Education. Santiago de Chile.

[14] New Perspectives in Special Education Contemporary philosophical debates, By Michael FarrellISBN 9780415504225 Published June 10, 2012 by Routledge 288 Pages.

[15] Palacios, Agustina.(2008), El modelo social de discapacidad: orígenes, caracterización y plasmación en la Convención Internacional sobre los Derechos de las Personas con Discapacidad, Ediciones Cinca S. A., Madrid, 2008, 523 páginas.

[16] Payá, José I.. (2010). Gaceta sindical: reflexióndebate, ISSN 1133-035X, No . 33, 2019 (Ejemplar dedicado a: Crítica y reivindicación del proyecto europeo), págs. 35-42.

[17] Revista latinoamericana de educación inclusiva ISSN: 07185480 Inicio: 2007, País: Chile. 